FINAL REPORT

U.S. Department of Energy

\title{
DETERMINING SIGNIFICANT ENDPOINTS FOR ECOLOGICAL RISK ANALYS ES
}

Principal Investigator: Thomas G. Hinton

Institution: University of Georgia, Savannah River Ecology Laboratory

Collaborators: Joel Bedford ${ }^{(1)}$, Justin Congdon ${ }^{(2)}$, David Scott ${ }^{(2)}$, Ward Whicker ${ }^{(1)}$

Institutions: ${ }^{(1)}$ Colorado State University; ${ }^{(2)}$ University of Georgia, Savannah River Ecology Laboratory

Project Number: 55410

Grant Number: TTP SRO-7-SP-22

Grant Project Officer: Dr. J. Beall

Project Dates: $1997-2000$ 


\section{TABLE OF CONTENTS}

Determining Significant Endpoints for Ecological Risk Analyses ......................................................................... 1

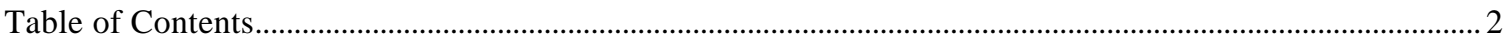

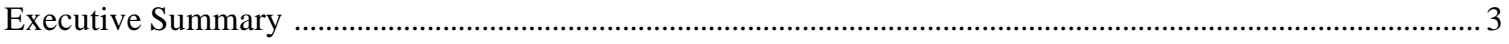

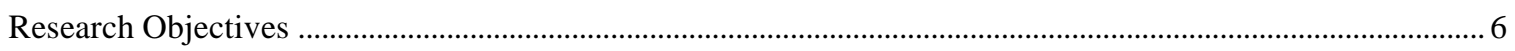

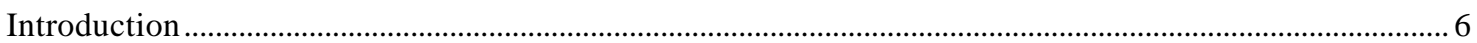

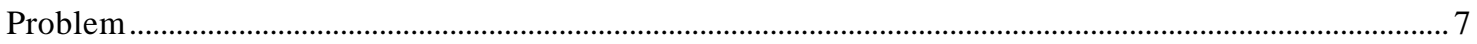

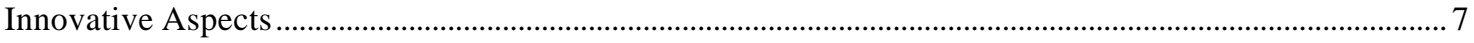

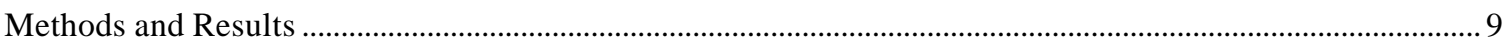

Development of Whole-Chromosome-Specific Probes .................................................................................... 9

Development of Culture Methods for Turtle Lymphocytes ......................................................................... 11

In Vivo Experiments ……………………………………………………………………………………. 12

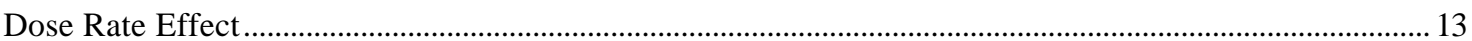

Applicability of Molecular Probe to Other Species and Conservation of Chromosome-1 1............................ 14

Field Experiments on the Savannah River Site ………............................................................................. 14

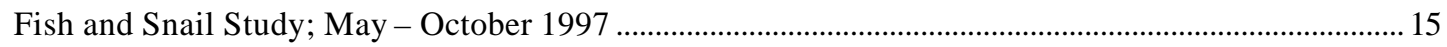

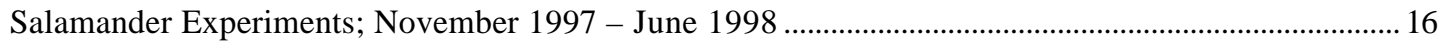

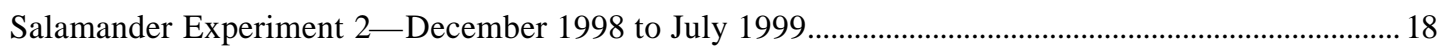

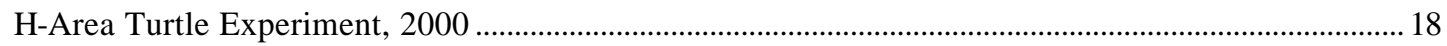

Frequency of Single Strand Breaks - 2000 ............................................................................................... 19

Development of Outdoor Mesocosm Irradiation Facility .............................................................................. 19

Relevance, Impact and Technology Transfer................................................................................................. 20

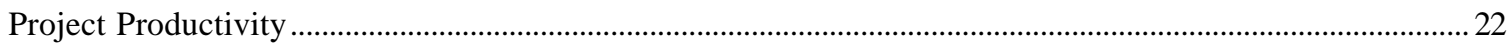

Personnel Supported/ Associated with project ………………………………………………………………. 24

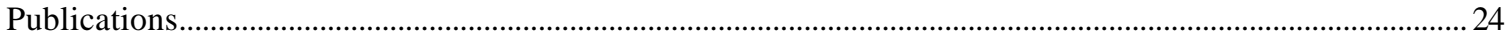

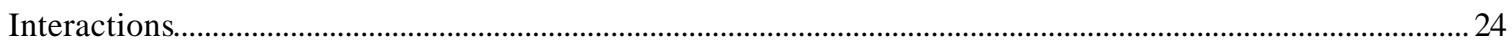

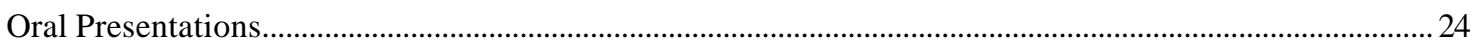

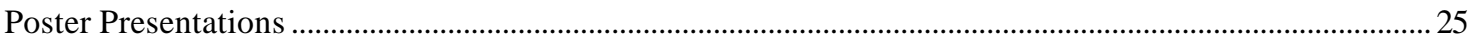

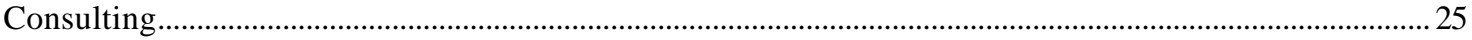

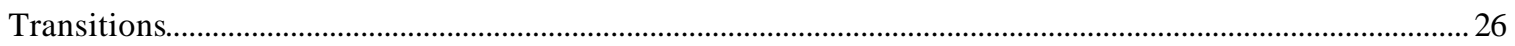

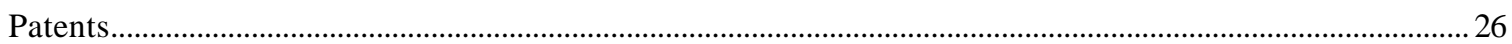

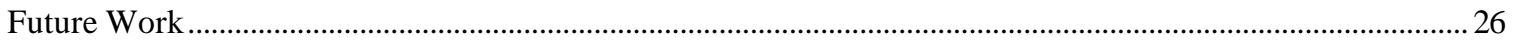

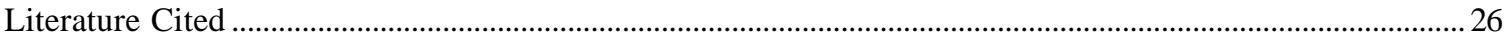




\section{EXECUTIVE SUMMARY}

Risk analyses, both human and ecological, are important factors in determining which DOE sites should be remediated, and in deciding if acceptable performance standards have been met. In sharp contrast to the well-defined and accepted parameters used to determine risks to humans, the parameters and endpoints used to estimate ecological risk are much debated, and dose-response relationships for chronic low-level exposures have not been established. Contaminants can affect all levels of biological organization, from molecules to ecosystems. Because recent technology has made it relatively easy to measure cellular and molecular abnormalities, much ecotoxicological research concentrates on these lower levels of biological organization, rather than documenting effects in individuals, populations, or communities. Ecological risk analyses based on sublethal endpoints (e.g. molecular damage), without an understanding of the impacts to higher levels of biological organization, could cause cleanup strategies on DOE sites to be overly conservative and unnecessarily expensive. We are interested in examining the ecological significance of radioactive and heavy metal contamination. We are assessing risks to nonhuman biota at higher levels of biological organization by using novel biological dosimeters in controlled, manipulative, dose/effects experiments, and by coupling molecular damage to more relevant responses that reflect the health of individuals and populations (such as metabolic rates, growth rates, age-specific survivorship, reproductive output, age at maturity and longevity).

Our research has concentrated on three areas: 1) developing a molecular probe to measure stable chromosomal aberrations know as reciprocal translocations, 2) constructing an outdoor mesocosm irradiation facility where the statistical power inherent in replicated mesocosms can be used to address the response of non-humans to exposures from low levels of radiation and metal contaminants, and 3) quantifying responses of organisms living in contaminated mesocosms and field sites.

We have successfully developed a biological dosimeter that measures cumulative damage in a longlived vertebrate, the yellow-bellied slider turtle. Constructing, testing and calibrating the probe were major undertakings and took an intense effort. The original methodology was a spin off of DOE's Human Genome Project, but to our knowledge this is the first time the technique has been applied to ecological risk questions. We constructed a whole-chromosome-painting probe using microdissection and polymerase chain reaction (PCR) amplification for a common species of turtle that inhabits many DOE sites 
(Mühlmann-Diaz, et al. in press). The turtle is a good model for some ecological risk questions because of its long life span and because it is know to inhabit numerous DOE contaminated sites. This was the first report of a fluorescent in situ hybridization whole-chromosome specific probe for a reptilian species. In fact, to the best of our knowledge, no whole-chromosome probes have been previously reported for nonmammalian species, other than for the sex chromosomes in a few avian species. We then developed a dose-response curve and examined the dose-rate effect under chronic exposures. The probe has been developed for chromosomes 1,2 , and 3, which represents $49 \%$ of the scorable genome (41\% of the total genome). Coverage of this fraction of the genome is a major achievement and will allow us to examine the effects of lower doses than would otherwise be feasible - maximum detection efficiency means fewer cells have to be scored and statistical precision will be maximized. We have found the molecular probe to work on all species of turtles tested to date, thus making it a generic tool applicability across numerous species and useful in a wide range of DOE sites. With this powerful tool we can now quantify the integrated, lifetime dose of turtles in contaminated environments, or those that are part of planned, manipulative experiments, even when their exposure histories are unknown.

The second major accomplishment was the development of an Outdoor Mesocosm Irradiation Facility. The facility is a powerful research tool that will be available to address numerous dose-response questions for many years. It has been designed specifically to examine questions related to long-term, chronic exposures to radiation. This unique facility offers two very strong advantages for conducting research on ecological risks. First, the mesocosm approach adds tremendous statistical power to experimental designs, and secondly, we are able to obtain precise estimates of dose and thereby establish accurate dose-response relationships. Our Outdoor Mesocosm Irradiation Facility consists of 50 specially designed fiberglass tanks in which we can maintain a variety of organisms. Thirty of the tanks have sealed ${ }^{137}$ Cs irradiators, containing three different activities, suspended above them. The irradiators were made specifically for this application and produce dose rates in exposed organisms that average 4, 40 or $400 \mathrm{mGy} \mathrm{d}^{-1}$.

Information generated from using these tools could radically transform how the significance of sublethal damage is viewed and, in turn, provide information essential to sound remediation decisions at DOE sites. 
Most of the experiments we had initially planned to conduct with these two new tools were delayed because two years of testing prototype irradiators was required before the vendor met our research design and specifications. Early versions of the irradiators scattered radiation such that human safety was of concern. Consequently, our original experimental designs using large-scale manipulations dependent upon numerous radiation sources were not possible during our first funding period. Additionally, because the radiation scatter from the source prototype was far larger than expected, the 50 -tank mesocosm facility could not be designed and installed until the ${ }^{137} \mathrm{Cs}$ source was modified and the exposure field from the source known (and minimized). Thus, our mesocosm experiments during the first funding period were hampered by a lack of: 1) ${ }^{137}$ Cs sources, and 2) permanently installed mesocosms with flow-through water. For example, in the winter of $1997 / 98$ only one ${ }^{137}$ Cs source (the prototype) was available for use with experimental mesocosms that did not have flowing water. Having only a single radiation source presented severe experimental design constraints. Although we attempted to conduct experiments (described below), for various reasons these attempts proved primarily to be learning experiences on the design constraints and husbandry techniques involved in the use of the large, shallow mesocosms. Our experience in these two years will benefit our experiments in years to come.

Even with these limitations, however, we were still very productive and published nine peer-reviewed manuscripts (see Publications section), and brought a Ph.D. student to successful fruition (Brant Ulsh, Radiation Biology, Colorado State University). A scientifically defensible endpoint for measuring ecological risks can only be determined once we understand the extent to which sublethal effects from contaminant exposure is detrimental at the individuals and population levels of biological organizations. A sound protocol for ecological risk assessment has far-reaching implications to the science of ecological risk analysis and broad, practical application at all DOE sites. 


\section{RESEARCH OBJECTIVES}

\section{Introduction}

Our interest is in obtaining a scientifically defensible endpoint for measuring ecological risks to populations exposed to chronic, low-level radiation, and radiation with concomitant exposure to chemicals. To do so, we believe that we must understand the extent to which molecular damage is detrimental at the individual and population levels of biological organization. Ecological risk analyses based on molecular damage, without an understanding of the impacts to higher levels of biological organization, could cause cleanup strategies on DOE sites to be overly conservative and unnecessarily expensive. Our goal is to determine the relevancy of sublethal cellular damage to the performance of individuals and populations. We think that we can achieve this by using novel biological dosimeters in controlled, manipulative dose/effects experiments, and by coupling changes in metabolic rates and energy allocation patterns to meaningful population response variables (such as age-specific survivorship, reproductive output, age at maturity and longevity).

Risk analyses, both human and ecological, are important factors in determining which DOE sites should be remediated, and in deciding if acceptable performance standards have been met. In sharp contrast to the well-defined and accepted parameters used to determine risks to humans, the parameters and endpoints used to estimate ecological risk are much debated, and dose-response relationships for chronic low-level exposures have not been established (Fig. 1). Contaminants can affect all levels of biological organization, from molecules to ecosystems. Because recent technology has made it relatively easy to measure cellular and molecular

abnormalities, much ecotoxicological research concentrates on these lower levels of biological organization rather than documenting effects in individuals, populations, or communities. While effects to individuals and populations may

Figure 1. Fundamental Differences Between Human and Ecological Risk Analyses

$\begin{array}{cccc}\text { Type } & \text { Unit of Observation } & \text { Endpoint } & \text { Dose-Response } \\ \text { Human } & \text { individual } & \begin{array}{c}\text { lifetime cancer } \\ \text { risk }\end{array} & \begin{array}{r}\text { relationships } \\ \text { established }\end{array}\end{array}$

Ecological

varies varies not established

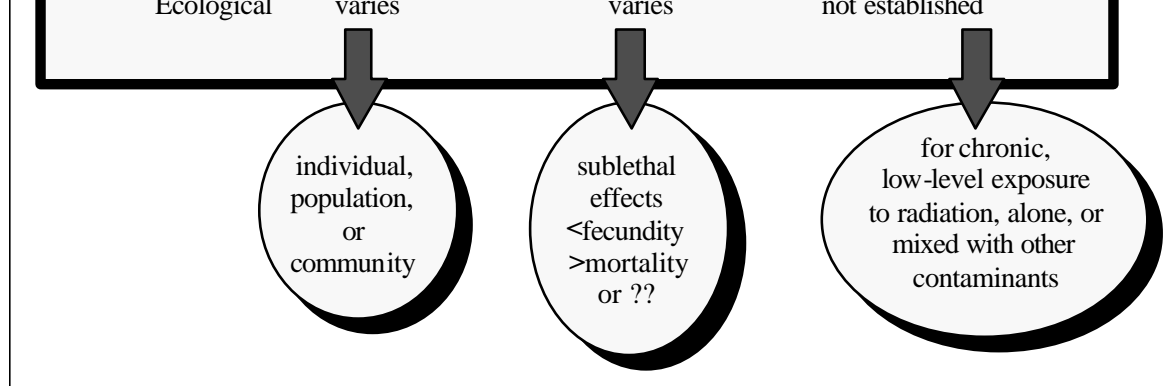

be more complex and difficult to measure, they are, nonetheless, more pertinent for ecological risk analyses (Forbes and Forbes 1994, Calow and Sibly 1990). Additionally, there is a large gap in our understanding the relationships of sublethal damage to effects observed in populations. How much cellular damage is required before an individual is affected, and in turn, how does individual damage translate to population 
level effects? Currently, there is a disparity in ecological risk analyses between what is generally measured and what needs to be measured if the population is the ultimate unit of interest.

\section{Problem}

Molecular damage generally represents a sublethal endpoint that may provide early warning of potential contaminant impact, but the consequences of molecular damage to higher levels of biological organization have not been well documented (Clements and Kiffney 1994, Underwood and Peterson 1988, Forbes and Calow 1996). Environmental risk analyses that use molecular effects as endpoints are of unknown value because of the uncertainties in quantifying the significance to individuals, populations and communities.

The problem of defining a proper endpoint for ecological risk analyses has wide-reaching implications. Inherent in any assessment of risk are the criteria used in determining what is a significant risk. Determining significance is particularly difficult in contaminated environments where low-level exposures produce subtle responses in organisms (Forbes and Calow 1996). Such low-level exposures to radionuclides and other contaminants occur on many DOE sites. The ultra-sensitivity of modern genetic techniques might allow investigators to document molecular damage in organisms inhabiting DOE sites with very low contaminant levels. However, if such molecular damage has little long-term impact on the physiology of the individual or the dynamics of the population, do contaminant levels at these sites actually pose significant environmental risks? Do they require multi-million dollar cleanup operations? In essence, a population-level dose-response curve is needed for ecological risk analyses. However, a meaningful dose-response curve is plagued by uncertainties in the measurement of individual doses, and with uncertainties in choosing which response variables are most appropriate (Hinton 1999).

\section{Innovative Aspects}

We developed two innovative tools necessary to address ecological risks in this funding period. The tools are: 1) a biological dosimeter, based on a molecular probe that allows us to quantify the frequency of chromosome aberrations in organisms whose lifetime exposure history is unknown, and 2) an outdoor mesocosm irradiation facility, where we can house organisms and conduct controlled, manipulative doseresponse experiments under chronic, low-level conditions. The tools are described below.

To address the problem of not having a biological dosimeter that reflects the level of cumulative damage in chronically exposed populations, we modified a method that was developed to measure stable chromosomal aberrations in humans known as reciprocal translocations. To our knowledge this is the first time the technique has been used in ecological risk analyses. The original methodology was a spin-off of DOE's human genome project and was made possible when complete 'libraries' of DNA sequences unique to individual human chromosomes became available (Pinkel et al. 1988). The method has been applied to Japanese atomic-bomb survivors and has been used as a biological dosimeter for individuals who received radiation exposures over 50 years ago (Lucus et al. 1992). In principle, the same approach can be used to study cumulative damage in the chromosomes of any organism. Until recently, however, such an endeavor would have required a monumental effort for each organism. It is now possible to achieve the same goal 
with less effort by using chromosome microdissection techniques followed by polymerase chain reaction (PCR) amplification to isolate the necessary probes. We adapted the technique for ecological risk analyses by developing a probe for a common species of turtle. The probe allows us to quantify the integrated lifetime dose in turtles whose exposure history is unknown. The turtle is a good model for examining risks from chronic low-level exposures because of its long life span of 35 years, and because many of DOE's radioactively contaminated environments are aquatic habitats inhabited by turtles.

The second major accomplishment was the development of an Outdoor Mesocosm Irradiation Facility. The facility is a powerful research tool that will be available to address numerous dose-response questions for many years. It has been designed specifically to examine questions related to long-term, chronic exposures to radiation. This unique facility offers two very strong advantages for conducting research on ecological risks. First, the mesocosm approach adds tremendous statistical power to experimental designs, and secondly, we are able to obtain precise estimates of dose and thereby establish accurate dose-response relationships. Our Outdoor Mesocosm Irradiation Facility consists of 50 specially designed fiberglass tanks in which we can maintain a variety of organisms. Currently the tanks are set up to house turtles and fish in a flow-through design. Thirty of the tanks have sealed ${ }^{137}$ Cs irradiators suspended above them (Fig. 2), that were made specifically for this application. The irradiators are designed with the ${ }^{137} \mathrm{Cs}$ source encapsulated within lead shielding. The source can be moved within the irradiator from a totally shielded compartment to one in which the irradiation beam is collimated in a downward facing cone, irradiating the confines of the mesocosm. When totally shielded, dose rates are below $0.05 \mathrm{mGy} \mathrm{h}^{-1}$ at $30 \mathrm{~cm}$ and researchers can safely access the animals. When moved to the irradiation position, dose rates received by the exposed organisms average 4, 40 and $400 \mathrm{mGy} \mathrm{d}^{-1}$, depending on source strength. We have 30 irradiators containing 0.02 , 0.2 or $2.0 \mathrm{Ci}$ sources.

Thermoluminescent dosimeters can be placed at various locations within the mesocosms to obtain average dose rates to which animals are

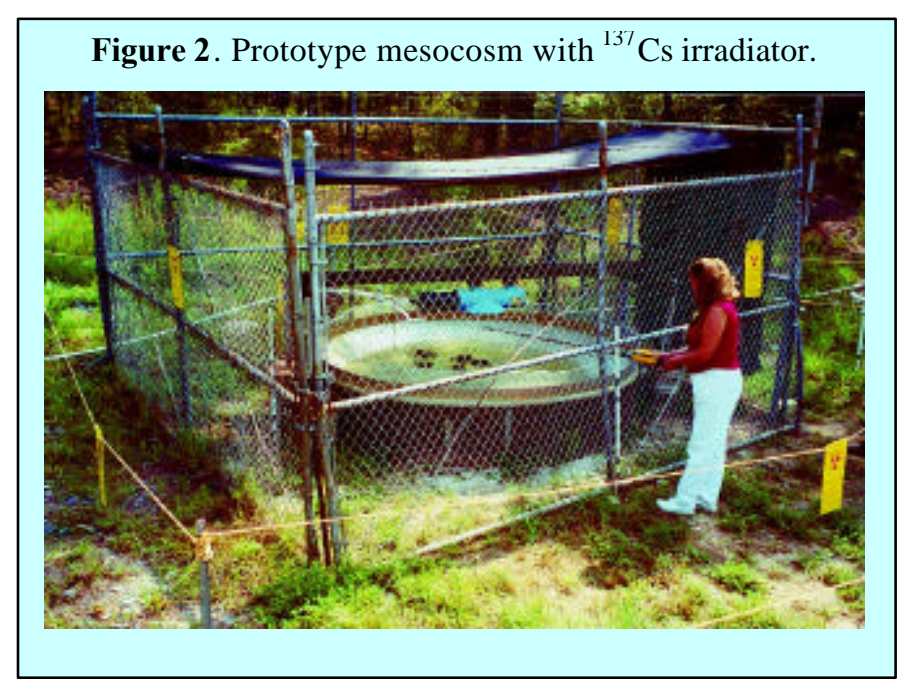
subjected, or directly on individual turtles using an attachment system that we devised. The mesocosms are designed to keep animals in conditions more natural than laboratory settings, similar to what has been successfully used in ecology and population biology (Morin 1983; Wilbur 1987; Rowe and Dunson 1994). The use of mesocosms occupies a middle position between realistic but uncontrolled field experiments, and highly controlled yet unrealistic laboratory experiments. Mesocosms allow us to apply specific treatments in a more controlled environment than large-scale field tests. Perhaps the greatest advantage of using 
mesocosms is the ability to replicate treatments to a degree that powerful statistical methods such as ANOVA can be used (Rowe and Dunson 1994).

Information generated from using these tools could radically transform how the significance of sublethal damage is viewed and, in turn, provide information essential to sound remediation decisions at DOE sites.

\section{METHODS AND RESULTS}

\section{Development of Whole-Chromosome-Specific Probes}

Over the course of the funding period, we successfully demonstrated the potential of biological dosimetry for assessing radiation exposures in ecological risk as sessments. These techniques, including fluorescence in situ hybridization (FISH), have been used in humans and rodents for years, but they have never been applied within ecological risks research because the requisite molecular probes did not exist. The probe we developed allows us to quantify the frequency of chromosome aberrations in a 1-3 mL blood sample, and in turn, estimate the cumulative live-time dose of the organism.

Constructing the probe was a major undertaking and took over a year of intense effort. We first constructed a whole-chromosome-painting probe for T. scripta chromosome \#1 using microdissection and polymerase chain reaction (PCR) amplification (Mühlmann-Diaz, et al. in press). This was the first report of a FISH whole-chromosome specific probe for a reptilian species. In fact, to the best of our knowledge, no whole-chromosome probes have been previously reported for nonmammalian species, other than for the sex chromosomes in a few avian species. The probe was constructed by microdissecting chromosomes from an embryonic T. scripta fibroblast cell line that we isolated from developing embryos.

With the probe in hand, we next demonstrated the ability of the FISH whole chromosome painting technique to detect radiation-induced chromosome exchanges in our embryonic fibroblast cell line. An example of such an exchange is shown in Figure 3. While symmetrical translocations do not result in loss of genetic material followed by cell death, they do result in the relocation of sections of DNA that almost certainly contain genes essential to the organism's survival. This can potentially lead to consequences far more serious for the organism than the death of a limited number of

Figure 3. FISH whole-chromosome painting shows radiation-induced chromosome exchange in fibroblast cells of the yellow-bellied turtle.

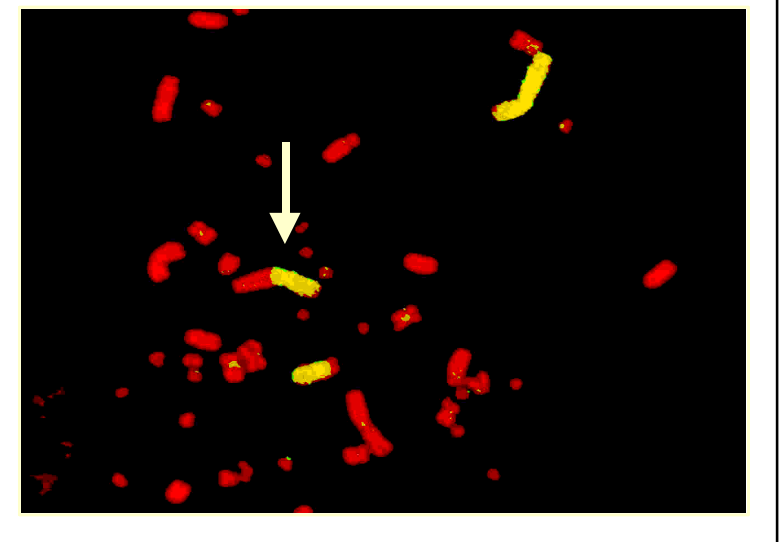

cells. Symmetrical translocations have been implicated in carcinogenesis when they occur in somatic (nongermline) cells. 
When translocations occur in germline stem cells, they can result in a condition known as translocation heterozygosity, as illustrated in Figure 4. Every cell in the offspring produced by a germline cell containing a symmetrical translocation will contain the translocation. Translocation heterozygotes are semi-sterile, and their reproductive success is reduced by $50 \%$. Of the viable offspring they do produce, half will be normal, and half will also be translocation heterozygotes. The potential of symmetrical translocations to lead to translocation heterozygosity, with the concomitant reduction in reproductive

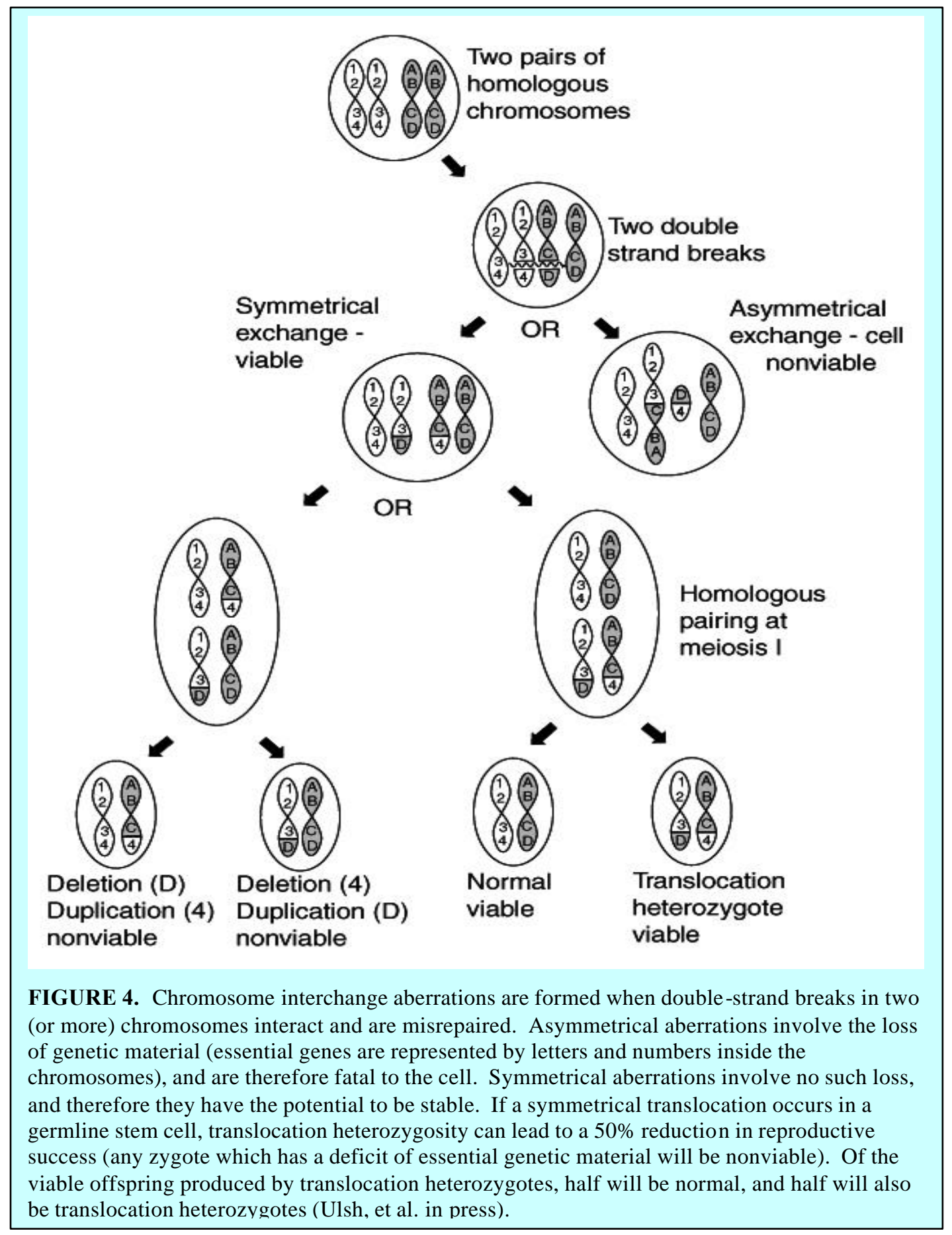


success, gives the frequency of these aberrations direct ecological relevance. Therefore, the endpoint of symmetrical translocation frequency may be more sensitive and relevant than traditional endpoints such as tissue residue analyses.

An important step in examining the usefulness of the turtle chromosome aberration system for our purposes was to compare the radiosensitivity using the turtle system with that for humans, which is already of proven usefulness. If turtle chromosomes were more radioresistant, in terms of aberration induction, by an order of magnitude or more, then the wisdom of utilizing turtles as a sentinel species would be highly questionable. We determined the dose-response relationship for induction of exchange aberrations under an "acute", high dose-rate exposure regimen strictly for the purpose of this turtle vs. human comparison. The main result of this study is shown in Figure 5, where the genome equivalent translocation frequency is plotted against dose for the turtle fibroblasts and for human fibroblasts treated under exactly the same conditions. We conclude from this that turtle fibroblasts are more radioresistant by a factor of about 2 for aberration induction. This result indicates that our approach will be of sufficient sensitivity to provide useful estimates of cumulative dose in turtles receiving exposures at the levels they may encounter in contaminated environments on DOE sites.

\section{Development of Culture Methods for Turtle Lymphocytes}

While it is essential to know the concentrations of contaminants within organisms, equally important knowledge is obtained by quantifying the effects caused from those contaminants. Radionuclides and many chemical compounds are both mutagenic and clastogenic, thus cytogenetic analyses can be particularly useful in determining the

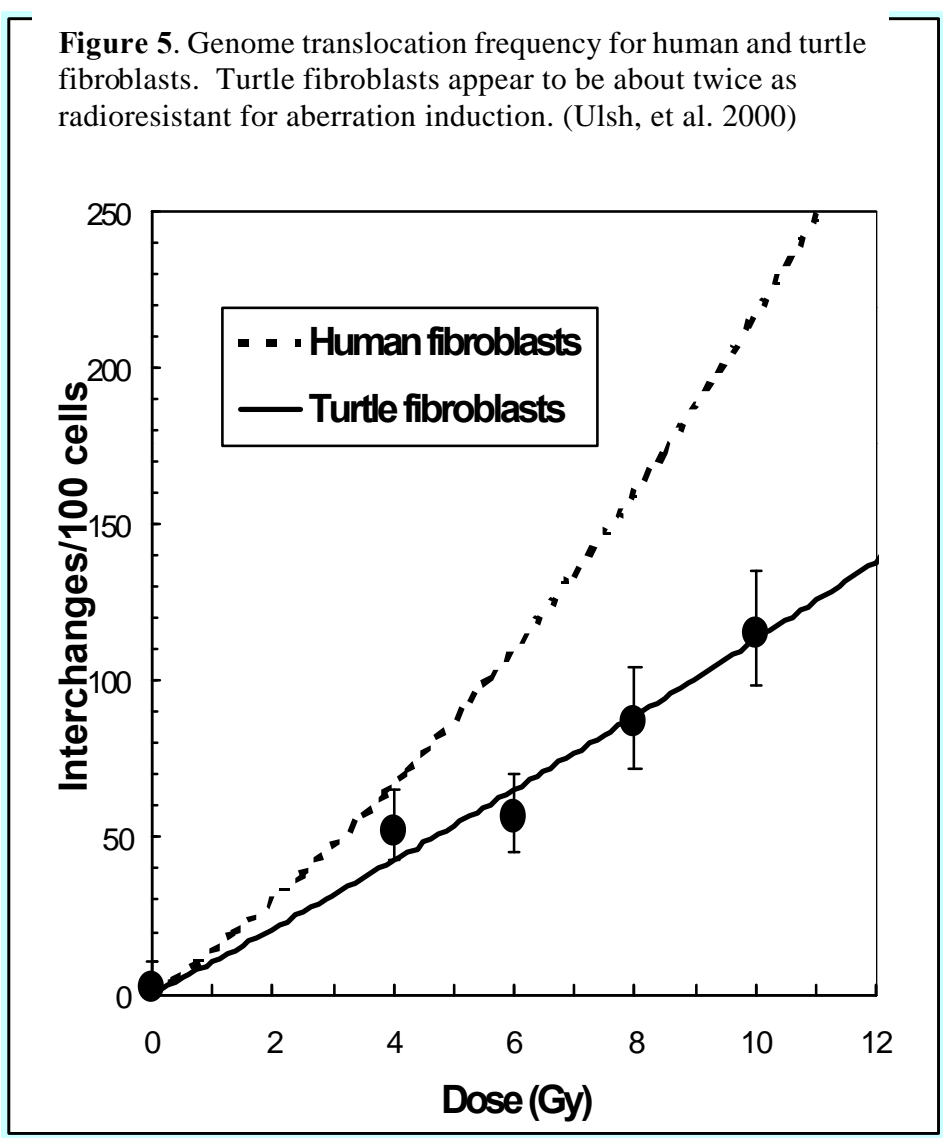
relevant biological effects of exposure to contaminants. Many early studies of contaminant effects on nonhumans were based on cytogenetic analyses of mitotic cells obtained from cultured spleen, heart, or kidney tissue. Collection of these tissues generally requires sacrificing animals and is not conducive to repeated sampling. Because our research examines the induction of chromosome aberrations in turtles by chronic, low-level exposure to radioactivity, a nonlethal sampling technique was necessary so that we could 
repeatedly collect cells from exposed animals. Furthermore, to assess aberrations in chromosomes, it is necessary to stimulate cells into the cell cycle, and to harvest them in mitosis. Finally, in contrast to karyotyping where only a few mitotic cells are necessary, large numbers of mitotic cells are required to quantify the effects of irradiation, because induced frequencies of aberrations per cell are relatively low. Sampling lymphocytes is an obvious way to satisfy these requirements, and thus much of our effort was spent developing turtle lymphocyte culture techniques.

We examined a variety of conditions and parameters relevant to turtle lymphocyte culture including: different mitogenic agents, alone and in combination; lymphocyte separation protocols; culture volume; time required to stimulate lymphocytes to mitosis; importance of humidity and gas exchange in culture incubation; suitability of different culture media; effects of varying serum concentrations; ability of interleukin-2 (IL-2) to stimulate lymphocyte growth and prevent apoptosis; and feasibility of inducing premature chromosome condensation. The work resulted in a manuscript (Ulsh et al. in press;b) in which we reported on the best conditions for obtaining mitotic cells from turtle lymphocytes. These were: (1) the combined use of phytohemagglutinin-M form (2\%) and lipopolysaccharides $(0.55: \mathrm{g} / \mathrm{ml}),(2)$ the use of $5 \%$ autologous turtle serum (as opposed to fetal bovine serum), and (3) collection of mitotic cells around 96 hours after mitogenic stimulation. We also found that human recombinant IL-2 did not increase the fraction of lymphocytes in mitosis over the range of concentrations tested and that calyculin A was ineffective at inducing premature chromosome condensation in turtle lymphocytes.

\section{In Vivo Experiments}

Finally, after successful probe development and lymphocyte culture, we conducted low-dose rate, in vivo irradiation of lymphocytes in 11 turtles. Samples from these animals were used to determine the dose-response relationship for symmetrical exchanges in the lymphocytes of animals subjected to exposure regimes similar to those they would experience in the field.

These results provide a calibration curve for use with free-ranging animals living in contaminated environments (Fig. 6). We verified the similarity of

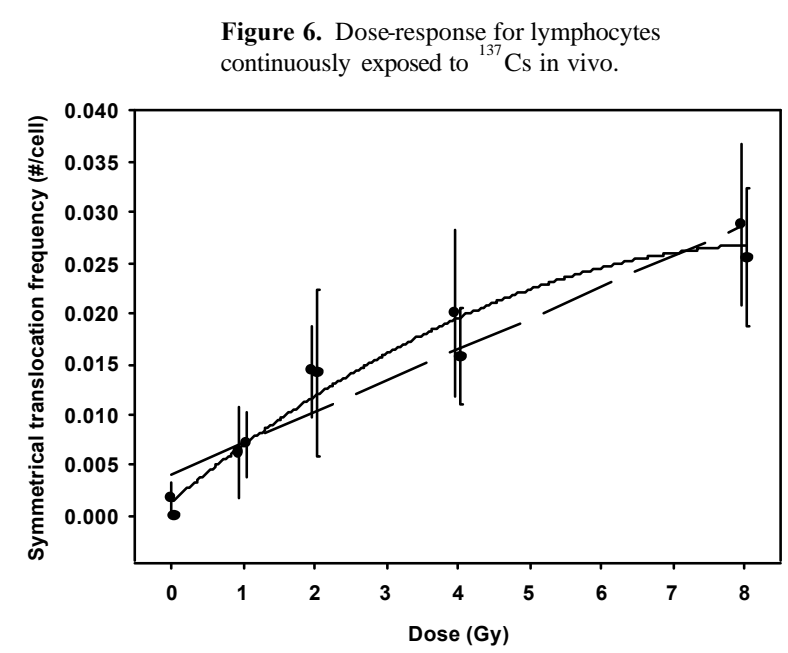

All irradiations were carried out at a dose-rate of $5.5 \mathrm{cGy} \mathrm{hr}^{-1}$. Each datapoint represents the net frequency (frequency after irradiationfrequency before irradiation) of apparently simple, complete symmetrical translocations involving chromosome -1. Datapoints are offset for clarity. The least square regression is shown (dashed line), however a linear-quadratic curve (solid line) gave a significantly better fit to the data $(\alpha=0.05)$ (Ulsh, et al. 2001)

the effects between the dose-rates used in this experiment and those in the field by using cultured fibroblasts to examine the dose-rate effect. 


\section{Dose Rate Effect}

Using a whole -chromosome FISH painting probe we previously developed for chromosome-1 of the yellow-bellied slider turtle (Trachemys scripta), we investigated the dose-rate effect for radiation-induced symmetrical translocations in T. scripta fibroblasts and lymphocytes (Fig. 7). The dose-rate below which no reduction in effect per unit dose is observed with further dose protraction was approximately $23 \mathrm{cGy}^{\mathrm{h} \mathrm{r}^{-1}}$

We estimated the wholegenome spontaneous background level of complete, apparently simple symmetrical translocations in T. scripta lymphocytes to be approximately $1.20 \times 10^{-3} /$ cell projected from aberrations occurring in chromosome-1. Similar spontaneous background levels reported for humans are some 5to 30 -fold higher, ranging from about $6 \times 10^{-3}$ to $3.4 \times 10^{-2}$ per cell. This relatively low background level for turtles would be a significant advantage for resolution of effects at low doses and dose-rates.

We also chronically irradiated turtles over a range of doses from 0-8 Gy delivered at approximately $5.5 \mathrm{cGy} \mathrm{hr}^{-1}$, and constructed a lymphocyte doseresponse curve for comp lete, apparently simple symmetrical
Figure 7. Comparison of the dose-rate effect observed for radiationinduced symmetrical translocations in $T$. scripta fibroblasts $(\bullet)$ with the dose-rate effect observed in other organisms using a variety of biological endpoints (Ulsh, et al. 2001).

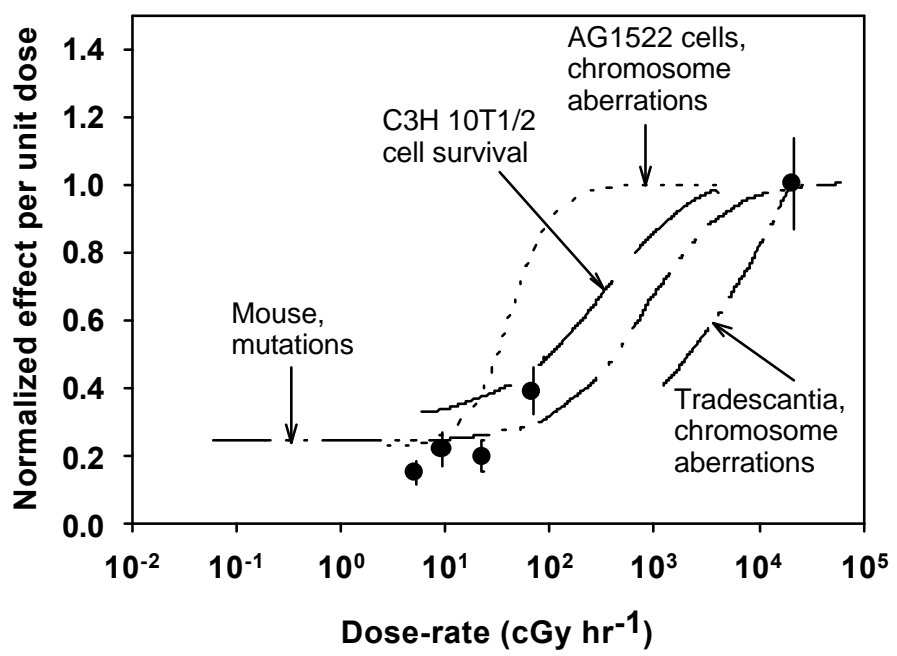

These include mutations in mice, survival of murine C3H 10T1/2 cells chromosome aberrations in human AG1522 fibroblasts, and chromosome exchanges in Tradescantia microspores observed by Giemsa staining . All data has been normalized by dividing each observation by the maximum effect observed in each study. The curves are 5-factor sigmoid fits to the norma lized data, except for the Tradescantia curve, which is a second order polynomial fit. Error bars on T. scripta data represent propagated errors due to Poisson counting statistics (one standard deviation).

translocations $\left(\mathrm{Y}_{\mathrm{T}}\right)$ suitable for use with animals chronically exposed to radiation in contaminated environments. The best fit calibration curve (not constrained through the zero dose estimate was of the form $\mathrm{Y}_{\mathrm{as}}=\mathrm{c}+\mathrm{aD}+\mathrm{bD}^{2}$, where $\mathrm{Y}_{\mathrm{as}}$ was the number of apparently simple symmetrical translocations per cell, D was the dose $(\mathrm{Gy}), \mathrm{a}=(0.0058 \pm 0.0009), \mathrm{b}=(-0.00033 \pm 0.00011)$, and $\mathrm{c}=(0.0015 \pm 0.0013)$. With additional whole -chromosome probes to improve sensitivity, environmental biodosimetry using stable chromosome translocations could provide a practical and genetically relevant measurement endpoint for ecological risk assessments and biomonitoring programs. 


\section{Applicability of Molecular Probe to Other Species and Conservation of Chromosome-1}

We also asked whether the wholechromosome specific painting library we produced for T. scripta chromosome \#1 would be useful for painting the \#1 chromosome in other turtle species. For these studies, we obtained blood samples fromfour turtle species as diverse as the desert tortoise and the loggerhead sea turtle. Figure 8 shows the T. scripta chromosome \#1 painting library hybridized to T. scripta (panel A), Chrysemys picta (panel B), Terrapene carolina (panel C), Gopherus agassizi (panel D), and Caretta caretta (panel E).

The $T$. scripta chromosome \#1 library hybridized exclusively to the \#1 chromosome of all species tested. This discovery had two important ramifications: first, it demonstrated that our probe will be useful in species from a variety of DOE facilities, and second, it proved a remarkable degree of conservation of chromosome structure over the course of turtle evolution. This contrasts with the situation for certain hominoid species where extensive
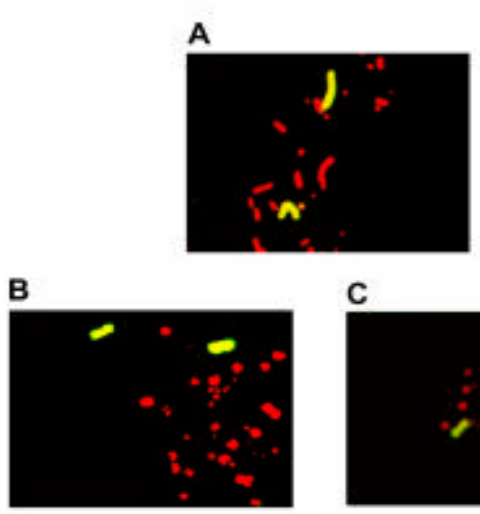

D

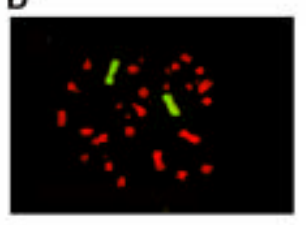

C

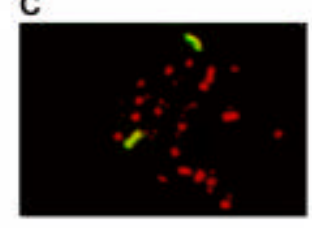

E

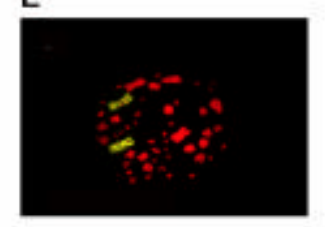

Figure 8. Whole chromosome painting by fluorescence in situ hybridization (FISH) using a T. scripta chromosome -1 library obtained by microdissection and DOP-PCR.

Chromosome-1 probe labeling and detection was with biotin dUTP and FITC avidin (yellow-green chromosomes, panels A, B, C, D, and F) or biotin dUTP and Texas Red avidin (pink chromosomes panel E). Panel A illustrates the $T$. scripta chromosome-1-specific probe library hybridized onto T. scripta mitotic cells. Panels B, C, D, and E utilized the same probe, but with hybridization onto C. picta (B), $T$. carolina (C); G. agassizii (D); or C. caretta (E) mitotic cells. Counterstaining was with propidium iodide (PI); Muhlmann-Diaz, et al. in press.

chromosomal rearrangements have been reported (Wienberg, and Stanyon 1995; 1997) during the past 20 million years (Andrews 1986; Sibley and Ahlquist 1984), despite a considerable degree of linkage conservation. The reason for a greater genomic stability in turtles is not known, but one possibility might be the lower rate of oxidative free radical production related to lower metabolic rate (Avise et al., 1992).

\section{Field Experiments on the Savannah River Site}

Our third area of research examined responses of organisms living in contaminated environments on the Savannah Rive Site. 
$\underline{\text { Fish and Snail Study; May - October } 1997}$

We conducted an experiment to compare the effects of environment on mosquitofish ( $\underline{\text { Gambusia }}$ ) and snails ( $\underline{\text { Campeloma }})$ reared in a radiation site (H-Area basins), metal contaminant site (coal ash basins) and a control pond (Fire Pond). The study was conducted from May to October 1997. Animals were kept within enclosures at each site for two months, then removed to the laboratory and measured for standard metabolic rate (SMR). One-third of the organisms from each site were to be returned to their site of initial exposure, and one-third would be transferred to each other site for the second half of the study (two months). The design resulted in nine treatments for each species (TABLE 1); pairwise comparisons of treatments allowed for tests of impacts of the stress environments during different life-stages.

TABLE 1. Design used in our first field experiment to test if stress from exposure to contaminants increases metabolic rates.

\begin{tabular}{|l|l|l|}
\hline Treatment & Exposure For 1st Two Months & Exposure For 2nd Two Months \\
\hline 1 & radiation & radiation \\
\hline 2 & radiation & trace elements \\
\hline 3 & radiation & unpolluted \\
\hline 4 & trace elements & trace elements \\
\hline 5 & trace elements & radiation \\
\hline 6 & trace elements & unpolluted \\
\hline 7 & unpolluted & unpolluted \\
\hline 8 & unpolluted & radiation \\
\hline 9 & unpolluted & trace elements \\
\hline
\end{tabular}

The experiment began when we placed 12 snails each into 12 20-L mesh and plastic containers at each site, and 15 mosquitofish each into 12 70-L mesh and plastic containers at each site (totals = 36 cages / species; 432 snail; 540 mosquitofish). Two months later, in mid-July, we removed surviving animals from all cages. Standard metabolic rates were estimated for survivors after which they were returned to field cages for the second portion of the study. Estimates of external dose rates to the animals at each location were derived from readings of thermoluminescent dosimeters (TLD) placed on the sediments and floating on the water surface (TABLE 2).

Surprisingly, all animals transplanted to the metal-polluted site (coal ash basins) died during the first half of the study, whereas survival in the radiation site and reference site was high (means \pm 1 SE: snails: $90.1 \pm 3.3 \%$ [Rad-site], $97.2 \pm 1.6 \%$ [control site]; mosquitofish: $71.5 \pm 4.7 \%$ [Rad-site], $72.1 \pm 3.7 \%$ [control site]). Standard metabolic rates of snails and mosquitofish did not differ between sites after the first half of the study. Because of total mortality in the metal contaminated site during the first half of the experiment, we used only two sites for the second portion, H-Area (radiation area) and the control site. 
Unfortunately, prior to the scheduled end of the study in October, 1997, a prolonged drought resulted in drying of the H-Area basins, and subsequent loss of experimental animals in that site.

TABLE 2. Net dose rates (mGy / day) from external irradiation estimated from thermoluminescent dosimeters placed on the sediment surface and floating on top of the water.

\begin{tabular}{|l|l|l|}
\hline Treatment & Dose Rate at Sediment Surface & Dose Rate at Surface of Water \\
\hline $\begin{array}{l}\text { H-Area Basin } \\
\text { Radiation) }\end{array}$ & $2.12 \pm 0.51(\mathrm{n}=24)$ & $1.31 \pm 0.07(\mathrm{n}=24)$ \\
\hline $\begin{array}{l}\text { Coal Ash Basin } \\
\text { (Metals) }\end{array}$ & $0.01 \pm 0.002(\mathrm{n}=3)$ & $0 \pm 0(\mathrm{n}=6) *$ \\
\hline $\begin{array}{l}\text { Fire Pond } \\
\text { Control) }\end{array}$ & $0 \pm 0(\mathrm{n}=6)^{*}$ & $0 \pm 0(\mathrm{n}=6) *$ \\
\hline
\end{tabular}

* Lower limit of detection $=0.0005 \mathrm{mGy} / \mathrm{day}$

Because of the complete mortality of fish and snails in the coal ash site during the first half of the study, we transplanted a second group of mosquitofish to the metal-contaminated basins and control site for one month (July - August, 1997), to determine if shorter-term exposure could provide insights into why the mortality occurred. After one month at the same densities as the initial studies, we removed survivors from each cage for measurement of SMR. After only one month of exposure, survival of fish in the metalpolluted site was very low $($ mean $=21 \%$ ) compared to the control $(75 \%)$. The low number of survivors from the metalpolluted site precluded proper measurement and analysis of metabolic rates.

It appears that, from a relative-toxicity standpoint, conditions in the metal contaminated site were more severe than in either the radiation or control sites. However, we were not able to quantify long-term effects on survival or sublethal responses due to early drying of the H-Area basins and subsequent loss of animals. Salamander Experiments; November 1997 - June 1998

This experiment was designed to examine the effects of radiation, metal contaminated sediments, and their combination on the larval growth and metabolic rate of marbled salamanders, Ambystoma opacum. Eight mesocosms were used in this pilot study - three with metal-contaminated sediments from SRS coal ash basins, three with clean sediments, and two were used to rear uncontaminated and contaminated food (zooplankton) for the salamander la rvae. The six treatment tanks were partitioned into four sections using screened inner pens. The four within-mesocosm pens were designated as control, move, low radiation, or high radiation treatment pens. Six larvae were placed in each inner pen, for a total of 24 larvae per mesocosm.

Because we had but a single ${ }^{137}$ Cs source (only one proto-type irradiator was constructed at this time, see Project Productivity section for an explanation), animals could not be irradiated continuously because that would have provided only one replicate of the radiation treatment. Although we recognized that frequent collection and moving of larvae from the mesocosm pens could pose an additional stress, we 
decided to irradiate the low- and high-radiation treatments animals every five days for 24-hr periods. Having a group of animals that were moved every five days, but not irradiated, assessed the effect of repeatedly moving larvae from their "home" mesocosm to the irradiation tank. All moved animals were housed in water in small plastic boxes for the 24-hr irradiation period. Two radiation doses were accomplished by placing the boxes at two distances from the source; the radiation treatments differed in dose by approximately a factor of 2 (high radiation total dose, $317 \pm 65 \mathrm{mGy}$; low radiation, $150 \pm 18$ $\mathrm{mGy})$.

Eggs from female A. opacum (from a small seasonal wetland on the SRS, Ginger's Bay) were collected in late November 1997. Eggs were held until February 10, 1998, and then flooded to initiate hatching. Hatchlings were held in pond water in small containers and fed a subsistence level of zooplankton weekly. Hatchlings were introduced to the four treatments in each mesocosm on 22 March 98. The salamanders were irradiated four times between 6-28 May 98 for a total of 186.3 hours.

We used a two-way, mixed model ANOVA to analyze the results from this experiment. There were no differences between the "move" and true "control" treatments, so these were combined into a single control treatment. When we compared the overall means of the metalcontaminated treatments with the cleansediment treatments, there was no significant effect of metals on salamander body mass $\left(\right.$ Table $3 ; F_{1,13}=$ $0.12, P>0.70)$ or size-adjusted metabolic rate $\left(\mathrm{F}_{1,13}=0.01, P>0.90\right)$. In addition, there was no effect of radiation treatment on either response variable (body mass, $\mathrm{F}_{2,13}=1.37, P>0.90$; metabolic rate, $\mathrm{F}_{2,13}=$ $0.01, P>0.95)$.

Table 3. Results of salamander experiment number-1. Mean values $( \pm 1 \mathrm{SE})$ for body mass $(\mathrm{g})$ at metamo rphosis and adjusted standard metabolic rate $\left(\mathrm{ml} \mathrm{O}_{2} / \mathrm{g} / \mathrm{hr}\right.$, in parentheses) of newly metamorphosed marbled salamanders (Ambystoma opacum).

\begin{tabular}{ccccc}
\hline & Control & Move & Low \\
only & radiation & High \\
& & & & radiation \\
Contaminated & $0.673 \pm 0.053$ & $0.692 \pm 0.063$ & $0.716 \pm 0.080$ & $0.597 \pm 0.040$ \\
Sediments & $(0.168 \pm 0.024)$ & $(0.167 \pm 0.030)$ & $(0.153 \pm 0.017)$ & $(0.143 \pm 0.027)$ \\
Clean & $0.834 \pm 0.093$ & $0.725 \pm 0.071$ & $0.635 \pm 0.034$ & $0.597 \pm 0.044$ \\
Sediments & $(0.133 \pm 0.019)$ & $(0.147 \pm 0.032)$ & $(0.139 \pm 0.011)$ & $(0.180 \pm 0.019)$
\end{tabular}

Numerous logistical problems in this pilot study potentially confounded our results. The fact that no animals survived in some pens created a severely unbalanced design, and possibly obscured some real trends. Thermal stress on animals that had to be moved to the irradiation tank posed a significant problem, 
as did the novel design (shape and depth) of the mesocosms. These problems forced us to re-evaluate our subsequent experimental design in the third year, and wait for DOE approval and delivery of all radiation sources before implementing an experimental test of radiation effects.

Salamander Experiment 2-December 1998 to July 1999

The potential effects of coal ash sediments alone were examined in experimental mesocosms using larval marbled salamanders (Ambystoma opacum). Eight tanks were established as artificialponds: four tanks contained ash basin sediments and four controls contained clean sediments. Tanks were filled with water in early February, leaves were added as a nutrient source, and zooplankton were added as a food source. Twenty hatchling A. opacum were placed in each tank in mid-February. A homogenized mixture of zooplankton was added to each tank as supplemental food approximately weekly throughout the course of the experiment. Larvae began to metamorphose in late April; recently metamorphosed salamanders were trapped from tanks and returned to the lab for measurements of body size and standard metabolic rate. Animals were also collected from a natural wetland for comparison. Individuals reared in the ash basin treatment metamorphosed approximately seven days earlier than clean tank animals, and at a smaller body size $(0.96 \pm 0.08 \mathrm{~g}$ wet mass vs. $1.22 \pm 0.04 \mathrm{~g})$. Survivorship did not differ between treatments, nor did size-adjusted metabolic rate $(\mathrm{mL} \mathrm{O} 2 / \mathrm{g} * \mathrm{hr})$. Numerous limb deformities were noted in the ash-basin treatment, however. The frequency of malformation that we observed $(\sim 50 \%)$ in animals from the ash basin treatment was far greater than the $\sim 3 \%$ found in natural populations or the level $(0 \%)$ observed in the control tank animals.

\section{H-Area Turtle Experiment, 2000}

We were unable to bring our fish and snail experiments in the radioactively contaminated $\mathrm{H}$-Area Radioactive Seepage Basins to full fruition because the pond dried up during a drought. In early 2000, we designed another experiment for the Radioactive Seepage Basins, but this time we used turtles, animals that we could recover if another drought occurred. The basins offer exciting research possibilities because they are among the more radioactively contaminated sites on the SRS, and the field site has more realistic exposure condition than laboratory experiments.

In this experiment, we had 15 adult male turtles, taken from uncontaminated control sites. Each animal had a background analysis of the frequency of chromosomal aberrations determined from their blood. Each animal had a waterproofed TLD attached to its shell. Ten animals were to be put in the basin on 1 April 2000 and then captured every 30 days so that blood samples could be withdrawn. Our goal was to examine the frequency of reciprocal translocations as a function of time in the basin and dose. The expected increased frequency in chromosomal aberrations was to be compared to other adult males kept as control animals. We were planning to keep the animals in the contaminated basin for approximately 9 months over which time they were expected to receive a total dose of about $0.5 \mathrm{~Gy}$, at a dose rate of about $1 \mathrm{mGy} \mathrm{d}^{-1}$. Animals were then to be removed from the contaminated area and maintained in clean mesocosms. The frequency of reciprocal translocations was to be assessed for an additional 2 years to 
determine the stability of the mutations. This experiment was going to provide valuable information on our biological dosimeter.

The experiment was not conducted due to the hesitancy of local DOE officials. They were concerned with the public perception of researchers placing animals within radioactively contaminated seepage basins, and the difficulties encountered if an animal should escape. The concerns were not abated with our attaching a radiotelemetry device to each animal, so that if they should escape from the fenced basin we could relocate them. A tremendous amount of the principal investigator's time was spent jumping through hoops to get this research initiated. In hind site, I suspect that the hoops were partially a stall tactic and that local DOE officials much preferred that we not conduct research in the basin.

Frequency of Single Strand Breaks - 2000

In another experiment, Dr. Betsy Sutherland from Brookhaven National Laboratory, examined DNA taken from tadpoles living in a clean pond and compared them to DNA taken from tadpoles living in a pond contaminated with coal fly ash. DNA was isolated in agarose plugs as double-stranded molecules, and the size of the single strands quantified on alkaline agarose gels. Results of five replicate gels indicated that the DNA from the ash basin animals $(14.6 \pm 1.0 \mathrm{~kb})$ was clearly smaller than that from animals living in the clean pond $(21.7 \pm 2.1 \mathrm{~kb})$. Using Unidirectional Pulsed Field electrophoresis the frequency of oxidized purines was also determined, based on the frequency of Fpg sites. The level of Fpg sites in DNA from the ash basin pond $(29.1 \pm 2.5$ per $\mathrm{Mb})$ was apparently lower than those in the clean pond $(34.8 \pm 2.4)$. These results suggest that the frequency of single strand breaks in the DNAs from animals from ash basin ponds is higher than that from animals from clean ponds. This has often been taken as a measure of DNA damage, and this may be the case. However, the similar-or even lower-levels of oxidized purines in DNA in the ash basin animals suggest that repair of such damages is increased in animals exposed to ash basin components. Thus the excess of single strand breaks in the ash basin animal DNAs could reflect that increased repair, as incision into the phosphodiester backbone is a normal step in repair of DNA damage. This possibility will be tested in future experiments.

\section{Development of Outdoor Mesocosm Irradiation Facility}

The irradiation facility is central to our experimental approach. It is truly a unique facility. The facility provides researchers tremendous opportunities to address difficult dose-effect questions. It was designed to house organisms in 50 outdoor tanks and to allow us considerable flexibility in conducting manipulative experiments under very controlled radiation exposure regimes. In addition to irradiation treatments, the facility will also accommodate experiments with other types of contaminants, alone or in combination with irradiation.

Considerable effort was spent during the first funding period designing a mesocosm suitable for a variety of species, as we anticipate using turtles, fish and amphibians as model organisms. Because each individual mesocosm has a sealed ${ }^{137} \mathrm{Cs}$ source suspended above it, additional design considerations were needed to insure homogeneity of the distribution of dose rates within the mesocosms, and to minimize the 
dose a human would receive working in the field of 50 mesocosms. A health physicist, Dr. John Campbell, was hired to calculate the mesocosm shape such that variation in dose rate within the tank would be minimal, while meeting the needs of animal husbandry. The result was a parabolic-shaped tank; $244 \mathrm{~cm}$ in diameter containing $30 \mathrm{~cm}$ of water and a ${ }^{137} \mathrm{Cs}$ point source suspended $61 \mathrm{~cm}$ above the water surface (Fig. 2). Because dose rate is greatest 0 to $10 \mathrm{~cm}$ below and 0 to $40-\mathrm{cm}$ perpendicular from the source, a second, inner container was designed to contain a subgroup of animals within that area. The inner container is about $90 \mathrm{~cm}$ in diameter at the water surface, with $30 \mathrm{~cm}$ between the bottom of the container and the floor of the large tank; thus, organism in the large tank can swim underneath the inner container. The inner container is perforated with holes, so there is free water exchange between the two tanks. By isolating an inner area, the overall spatial variation in exposure is substantially reduced, and the possibility to run two simultaneous experiments within each tank is possible. The highest dose rates are in the area occupied by the inner container, by excluding animals from this area the dose rate within the large tank is kept to within a factor of 3 , similar to the dose rates within the smaller inner container.

\section{RELEVANCE, IMPACT AND TECHNOLOGY TRANSFER}

How does this new scientific knowledge focus on critical DOE environmental management problems?

Risk analyses, both human and ecological, are important factors in determining which DOE sites should be remediated, and in deciding if acceptable performance standards have been met. In sharp contrast to the well-defined and accepted parameters used to determine risks to humans, the parameters and endpoints used to estimate ecological risk are much debated, and dose-response relationships for chronic low-level exposures have not been established. The problem of defining a proper endpoint for ecological risk analyses has wide-reaching implications. Inherent in any assessment of risk are the criteria used in determining what is a significant risk. Determining significance is particularly difficult in contaminated environments where low-level exposures produce subtle responses in organisms (Forbes and Calow 1996). Such low-level exposures to radionuclides and other contaminants occur on many DOE sites.

How will the new scientific knowledge that is generated by this project improve technologies and cleanup approaches to significantly reduce future costs, schedules, and risks and meet DOE compliance requirements?

Inadequate knowledge about ecological risks could result in DOE having to take an unnecessarily conservative approach to cleanup, resulting in a substantial escalation of costs. A scientifically defensible endpoint for measuring ecological risks can only be determined once we understand the extent to which sublethal effects (e.g. molecular damage) from contaminant exposure is detrimental at the individual and population levels of biological organization.

To what extent does the new scientific knowledge bridge the gap between broad fundamental research that has wide-ranging applications and the timeliness to meet needs-driven applied technology development?

A sound protocol for ecological risk assessment will have far-reaching implications to the science of ecological risk analysis and broad, practical application at all DOE sites. 
What is the project's impact on individuals, laboratories, departments, and institutions? Will results be used? If so, how will they be used, by whom, and when?

The largest impact to an individual was to B. Ulsh,, who received a Ph.D. from research he conducted while working on the project. The principal investigator also benefited from the experience of leading a complex, multi-disciplinary research project. All of the collaborators benefited from the interaction with each other. We were all experts in some small aspect of the work, and likewise ignorant in others. Thus, each of us learned from our colleagues, as well as passed our expertise on to others.

The development of whole-chromosome probes for a turtle species is especially timely, as considerable debate currently exists over the evolutionary relationship between turtles, other reptilian species, and avian species. Recent molecular evidence appears to be at odds with phylogenies based on the fossil record and on morphology (Hedges and Poling 1999). The development of whole-chromosome libraries for turtles can provide independent cytogenetic evidence of genomic relationships and contribute to this debate. The application of microdissection, PCR and FISH to generate whole-chromosome libraries for nonmammalian organisms will greatly expand the tools available for comparative genomics, help to clarify evolutionary relationships, and expand the reach of genetic ecotoxicology to important species of organisms not previously examined.

Additionally, the Outdoor Mesocosm Irradiation Facility is a powerful research facility that will be reused many, many times to facilitate our understanding risks from contaminated environments. We will continue our work in the facility, and others (i.e. Dr. Betsy Sutherland from Brookhaven National Laboratory) plan to use the facility relative to DOE funded low-dose research. Some have even suggested that the area should become a DOE-Users Facility. The lack of adjacent housing for visiting scientists currently deters that imitative.

The principal investigator has taken knowledge gained from this research and used it in his work with the Department of Energy's Biota Dose Assessment Group (BDAG). BDAG is currently reviewing ecological risk concepts and establishing guidelines for conducting ecological risks on DOE facilities. Are large-scale trials warranted? What difference has the project made? Now that the project is complete, what new capacity, equipment, or expertise has been developed?

This research developed two new powerful tools. A molecular probe that can be used as a biological dosimeter to determine the integrated lifetime dose to exposed turtles. The probe was developed using techniques formulated during the DOE human genome project. We are the first to apply in to reptiles and to ecological risk questions. Others will use the probe for similar questions, as well as other applications. For example, we saw its utility to address questions about the genetic relationships among diverse species (Ulsh et al. 2000). Recent molecular evidence appears to be at odds with phylogenies based on the fossil record and on morphology (Hedges and Poling 1999). The development of whole -chromosome libraries for turtles can provide independent cytogenetic evidence of genomic relationships and contribute to this debate. The application of microdissection, PCR and FISH to generate whole -chromosome libraries for nonmammalian organisms will greatly expand the tools available for comparative genomics, help to clarify 
evolutionary relationships, and expand the reach of genetic ecotoxicology to important species of organisms not previously examined.

How have the scientific capabilities of collaborating scientists been improved?

All of the scientists involved expanded their knowledge because of this project. The research funded the education of a Ph.D. student. The research tools developed during the project (a biological dosimeter and an outdoor mesocosm irradiation facility) will be useful to the collaborators in future research projects. How has this research advanced our understanding in the area?

Our work provides a blueprint for determination of appropriate lymphocyte culture conditions in turtles and other reptiles. The results of these experiments will also be of interest to researchers in comparative and veterinary immunology. Lymphocytes mediate immune response, and they are therefore used in immunologic assays. The inclusion of turtles in immunologic studies could provide a valuable perspective on the response of these animals to xenobiotic exposures, as stimulation of the immune system is frequently a component of the stress response elicited by such exposures.

What additional scientific or other hurdles must be overcome before the results of this project can be successfully applied to DOE Environmental Management problems?

Having developed the necessary tools to fully address the research problem, we are now faced with funding constraints. DOE recently rejected our request for an EMSP grant renewal. We have since placed a pre-proposal into the DOE low-dose call.

Additional problems occur at the local level. Local DOE officials are often not as interested in facilitating DOE funded research as are their Washington counterparts, particularly if the research requires compromise to their existing operations. Local DOE officials and/or their contractors sometimes have difficulties relating to research. This is particular true in the area of health physics. Decisions related to the use of radionuclides on DOEsites are often governed by a fear of liability, rather than logic, safety or derived benefits. Such an attitude makes it extremely difficult to address radiological research questions. Have any other government agencies or private enterprises expressed interest in the project?

No, although the research should be of interest to the Environmental Protection Agency and the National Institutes of Health.

\section{PROJECT PRODUCTIVITY}

In the fall of 1997, we received our first irradiator, a $1 \mathrm{Ci}\left(3.7 \times 10^{10} \mathrm{~Bq}\right){ }^{137} \mathrm{Cs}$ source encased in lead shielding with a portal to which the source could be moved to for irradiating. Because this prototype did not meet the design specifications promised to us by the vendor, it could not be used as the model for the additional sources. Two years of testing prototypes were required before we received an irradiator that met our research design and specifications. Early prototypes were unsuccessful because radiation scatter exposed workers to unacceptable levels, and exposure fields within a mesocosm lacked sufficient homogeneity. Figure 9 shows how sidescatter, measured at the circumference of a mesoscom's upper rim, was reduced in our final irradiator when compared to an earlier prototype. 


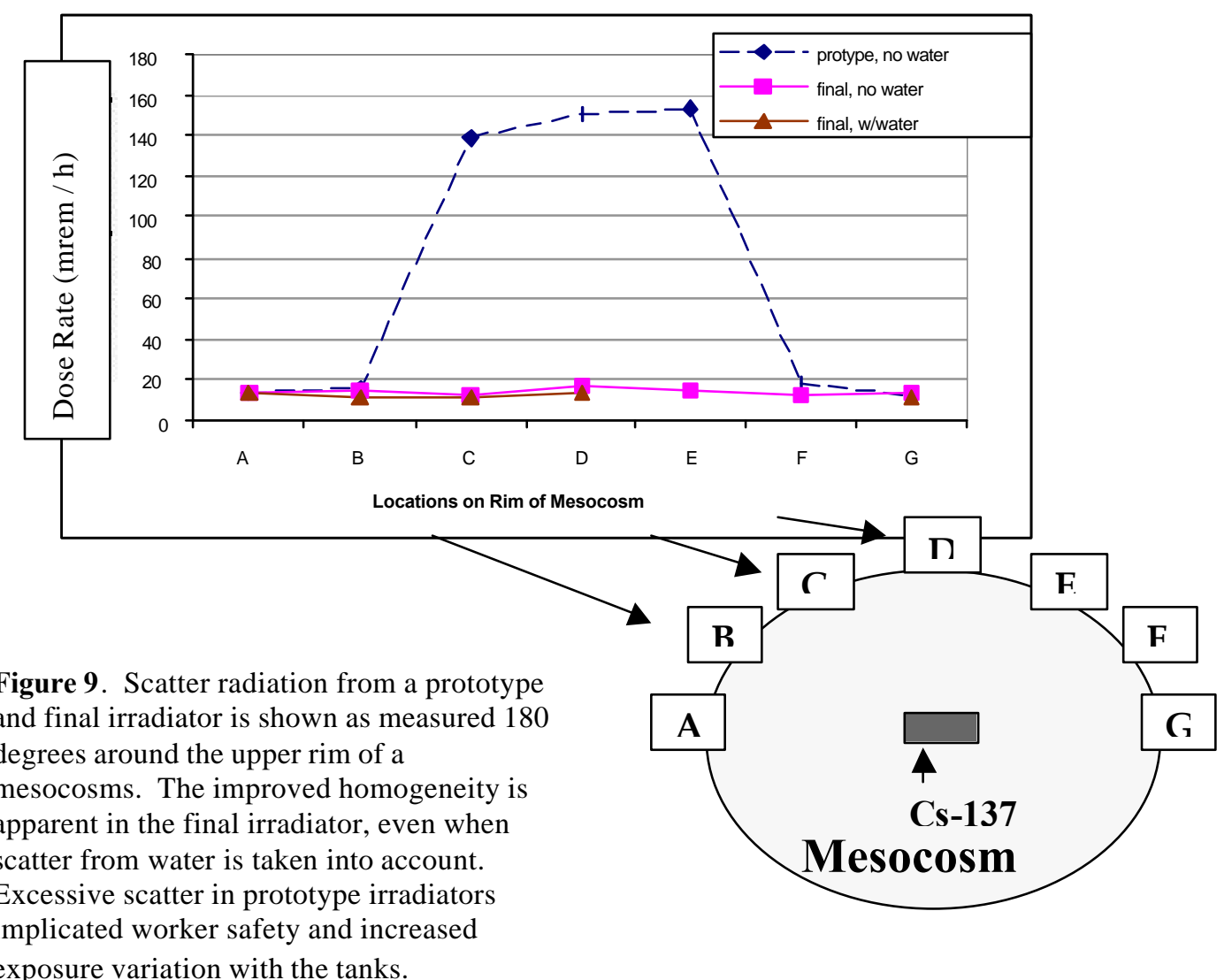

exposure variation with the tanks.

When the vendor's irradiator finally met our specifications, we were then surprised to be confronted with another delay. Historically, SREL has used the local DOE subcontractor's license (WSRC, Westinghouse Savannah River Company) for purchasing radioactive materials. This time, however, we were delayed by WSRC's refusal to order the irradiators because of their concerns over liability issues. A new Memorandum of Understanding between SREL and WSRC was required before the order was placed. The 30 irradiators were pro mised by the vendor to be at SREL by October 30, 1999, but were no received until the spring of 2000. We bring this topic to your attention only to alert reviewers of the bureaucratic, legal and safety issues from DOE, NRC, South Carolina and WSRC that must be patiently and systematically dealt with in order to conduct this type of research.

Consequently, large-scale experimental manipulations dependent upon numerous radiation sources were not possible during our first funding period. Additionally, because the radiation scatter from the source prototype was far larger than expected (Fig. 9), the 50-tank mesocosm facility could not be designed and installed until the ${ }^{137} \mathrm{Cs}$ source was modified and the exposure field from the source known (and minimized). Thus, our mesocosm experiments during the first funding period were hampered by a lack of: 1) ${ }^{137}$ Cs sources, and 2) permanently installed mesocosms with flow-through water. For example, in the winter of $1997 / 98$ only one ${ }^{137}$ Cs source (the prototype) was available for use with experimental 
mesocosms that did not have flowing water. Having only a single radiation source presented severe experimental design constraints. Although we attempted to conduct experiments (described above), for various reasons these attempts proved primarily to be learning experiences on the design constraints and husbandry techniques involved in the use of the large, shallow mesocosms. Our experience in these two years will benefit our experiments in years to come.

\section{PERSONNEL SUPPORTED/ ASSOCIATED WITH PROJECT}

Dr. Tom Hinton, faculty, University of Georgia

Dr. Justin Congdon, faculty, University of Georgia

Dr. Chris Rowe, post-doc, University of Georgia

Dr. Joel Bedford, faculty, Colorado State University

Dr. Ward Whicker, faculty, Colorado State University

David Scott, research coordinator, University of Georgia

Maria Mühlmann-Díaz, research affiliate, Colorado State University

Brant Ulsh, Ph.D. student, Colorado State University

\section{PUBLICATIONS}

Ulsh, B. A., F. W. Whicker, T. G. Hinton, J. D. Congdon, and J. S. Bedford. 2001 Chromosome translocations in T. scripta: the dose-rate effect and in vivo lymphocyte radiation response. Radiation Research 155:63-73.

Ulsh, B. A., M. C. Mühlmann-Díaz, F. W. Whicker, T. G. Hinton, J. D. Congdon, and J. S. Bedford. 2000. Chromosome translocations in turtles: A biomarker in a sentinel animal for ecological dosimetry. Radiation Research 153, 752-759.

Whicker, F.W. 2000. Radioecology: Relevance to problems of the new millennium. Journal of Environmental Radioactivity 50:173-178.

Hinton, T. G. 2000. Strong inference, science fairs and radioecology. J. Environ. Radioactivity 51:277279

Hinton, T. G. 1999. Risks from Exposure to Radiation. Chapter 14. In: Fundamentals of Ecotoxicology, M. C. Newman (Ed.), pp. 251-278, Ann Arbor Press, Chelsea, MI.

Mühlmann-Díaz, M. C., B. A. Ulsh, F. W. Whicker, T. G. Hinton, J. D. Congdon, J. F. Robinson, and J. S. Bedford. (in press) Conservation of chromosome -1 in turtles over 66 million years. Cytogenetics and Cell Genetics

Congdon, J. D., A. E. Dunham, W. A. Hopkins, C. L. Rowe, and T. G. Hinton. (in press) Resourceallocation based life histories: A conceptual basis for studies of ecological toxicology. Environmental Toxicology and Chemistry

Ulsh, B. A., L. Dugan, T. G. Hinton, F. W. Whicker, and J. S. Bedford. (in press) Environmental biodosimetry: A biologically relevant tool for ecological risk assessment and biomonitoring. Journal of Environmental Radioactivity

Ulsh, B. A., J. D. Congdon, T. G. Hinton, F. W. Whicker, and J. S. Bedford. (in press) Culture methods for turtle lymphocytes. Methods in Cell Science

\section{INTERACTIONS}

\section{Oral Presentations}

- Platform presentation: Chromosome translocations in turtles: a biomarker in a sentinel animal for enviornmental biodosimetry. B. Ulsh, Society of Environmental Toxicology and Chemistry Annual Meeting, Nashville, TN, November, 2000

- Invited Speaker: Determining significant endpoints for ecological risk analyses. T. G. Hinton, International Atomic Energy Agency. August 2000. Vienna, Austria.

- Invited Speaker: Including reptiles and amphibians in ecological risk assessment. B. Ulsh, Wildlife Applications in Remediation Decision Making Conference, 1999, Denver, CO. 
- Invited Speaker: A chromosome runs through it. J. S. Bedford, The Thirty-Sixth Failla Award Lecture. Presented at the Eleventh International Congress of Radiation Research, July 1999, Dublin, Ireland.

- Invited Speaker: Determining significant endpoints for ecological risk analyses. T. G. Hinton, DOE Biota Dose Assessment Group. August 1999, Wash. DC.

- Invited Speaker: Protection of the environment from ionizing radiation: an international perspective. F. W. Whicker, $2^{\text {nd }}$ International Symposium on Ionizing Radiation. May 1999, Ottowa, Ontario, Canada.

- Invited Speaker: Future directions in environmental and radioecological research. F.W. Whicker, 44th Annual Meeting of the Health Physics Society. June 1999, Philadelphia, PA.

\section{Poster Presentations}

"Chromosome translocations in turtles: a biomarker in a sentinel animal for environmental biodosimetry" International Workshop on Comparative Radiobiology

Dublin, Ireland, October, 2000; B. Ulsh

"Chromosome translocations in turtles: a biomarker for radiation exposure" Wildlife Applications in Remediation Decision Making Conference Denver, CO, 1999; B. Ulsh

"Determining significant endpoints for ecological risk analyses". DOE Environmental Management Science Program Workshop. Atlanta, GA April 1999; T. Hinton

"Chromosome translocations in turtles's a biomarker for radiation exposure" International Congress on Radiation Research Dublin, Ireland, 1999; B. Ulsh

"Non-mammalian whole chromosome FISH probes and microdissection". Third International Clinical FISH Symposium. Steamboat Springs, CO. Feb. 1998. M. Mühlmann-Díaz

"Development of a whole-chromosome painting probe for T. scripta" Radiation Research Society Annual Meeting Louisville, KY, April 1998; B. Ulsh

"Determining significant endpoints for ecological risk analyses". DOE Environmental Management Science Program Workshop. Chicago, IL. July 1998; T. Hinton

"Determining significant endpoints for ecological risk analyses". DOE/DoD/EPA Strategic Environmental Research and Development Program. Washington, D.C. Dec. 1998; T. Hinton

\section{Consulting}

Protection of the environment from ionizing radiation, and the associated questions we are addressing through the EMSP program, are of national and international interest. I was asked to present our results and provide guidance at two important meetings. Nationally, the DOE is formulating guidance on how to conduct ecological risk analyses through their Biota Dose Assessment Committee. I was asked to review their documents, and present our research results at a meeting in Aug. 1999. At the international level, I was asked to be on a panel of experts at an International Atomic Energy Agency meeting in Vienna, Austria (Aug. 2000). We addressed the issue of what are the appropriate endpoints when conducting ecological risk analyses, and whether or not the environment is automatically protected when exposures are limited to the point that humans are protected. 


\section{TRANSITIONS}

None at this time

\section{PATENTS}

None

\section{FUTURE WORK}

With the tools developed in this funding period, and the experience gained, we are poised to make major contributions to the field of ecological risk analyses. We have the tools to address the issue of whether current international radiation guidelines for permissible exposure levels to nonhumans adequately protect the biota. We plan to research combinations of stresses to individuals (e.g. irradiation plus heavy metals) and see if resulting effects are additive or multiplicative. Our Outdoor Mesocosm Irradiation

Facility and the biological dosimeter we developed is a rigorous addition to experimental designs aimed at understanding how contaminants effect individuals and populations. An entire suite of hypotheses, along with the experimental designs, were presented in our 2000 EMSP renewal request.

\section{LITERATURE CITED}

Andrews, P.: 1986. Fossil evidence on human origins and dispersal. Cold Spring Harbor Symposia on Quantitative Biology 51 Pt 1:419-428.

Avise, J. C., Bowen, B. W., Lamb, T., Meylan, A. B., and Bermingham, E.: 1992. Mitochondrial DNA evolution at a turtle's pace: evidence for low genetic variability and reduced microevolutionary rate in the Testudines. Molecular Biology \& Evolution 9:457-473.

Calow, P. and R. M. Sibly. 1990. A physiological basis of population processes: ecological implications. Funct. Ecol 4:282-288.

Clements, W. H. and P. M. Kiffney. 1994. Environ. Tox. and Chem. 13:357-359.

Forbes, V. E. and T. L. Forbes. 1994. Ecotoxicology in Theory and Practice. Chapman and Hall, London.

Forbes, V. E. and P. Calow. 1996. Costs of living with contaminants: implications for assessing low-level exposures. Belle Newsletter, Univ. of MA. 4(3):1-8.

Hinton, T. G. 1999. Chapter 14. Risks from Exposure to Radiation. In: Fundamentals of Ecotoxicology, M. C. Newman (Ed.), pp. 251-278, Ann Arbor Press, Chelsea, MI.

Lucas J. N., A. Awa, T. Straume, M. Poggensee, Y. Kodama, M. Nakano, K. Ohtake, H.U. Weier, D. Pinkel, J. Gray and G. Littlefield. 1992. Rapid traslocation frequency analysis in humans decades after exposure to ionizing radiation. Int. J. Radiat. Bio. 62:53-63.

Morin, P. J. 1983. Predation, competition, and the species competition at larvalanuran guilds. Ecological Monographs 53:119-138.

Mühlmann-Díaz, M. C., B. A. Ulsh, F. W. Whicker, T. G. Hinton, J. D. Congdon, J. F. Robinson, and J. S. Bedford. (in press) Conservation of chromosome -1 in turtles over 66 million years. Cytogenetics and Cell Genetics

Pinkel D., J. Landegetn, C. Collins, J. Fuscoe, R. Segraves, J. Lucas and J. W. Gray. 1988. Fluorescence in situ hybridization with human chromosome-specific libraries: Detection of trisomy 21 and translocations of chromosome 4. Proc. Natl. Acad. Sci. 85:9138-9142.

Rowe, C. L, and W. A. Dunson. 1994. The value of simulated pond communities in mesocosms for studies of amphibian ecology and ecotoxicology. J. Herpetology 28:346-356.

Sibley, C. G. and Ahlquist, J. E.: 1984. The phylogeny of the hominoid primates, as indicated by DNADNA hybridization. Journal of Molecular Evolution 20:2-15. 
Ulsh, B. A., F. W. Whicker, T. G. Hinton, J. D. Congdon, and J. S. Bedford. 2001 Chromosome translocations in T. scripta: the dose-rate effect and in vivo lymphocyte radiation response. Radiation Research 155:63-73.

Ulsh, B. A., M. C. Mühlmann-Díaz, F. W. Whicker, T. G. Hinton, J. D. Congdon, and J. S. Bedford. 2000. Chromosome translocations in turtles: A biomarker in a sentinel animal for ecological dosimetry. Radiation Research 153, 752-759.

Ulsh, B. A., L. Dugan, T. G. Hinton, F. W. Whicker, and J. S. Bedford. (in press) Environmental biodosimetry: A biologically relevant tool for ecological risk assessment and biomonitoring. Journal of Environmental Radioactivity

Ulsh, B. A., J. D. Congdon, T. G. Hinton, F. W. Whicker, and J. S. Bedford. (in press;b) Culture methods for turtle lymphocytes. Methods in Cell Science

Underwood A. J. and C. H. Peterson 1988. Mar Ecolo. Prog. Ser 46:227-234.

Wilbur, H. M. 1987. Regulation and structure in complex systems: experimental temporary pond communities. Ecology 68:1437-1452.

Wienberg, J. and Stanyon, R.: 1995. Chromosome painting in mammals as an approach to comparative genomics. Current Opinion in Genetics \& Development 5:792-797.

Wienberg, J. and Stanyon, R.: Comparative painting of mammalian chromosomes. Current Opinion in Genetics \& Development 7:784-791 (1997). 